\title{
A Surveillance System of a Military Harbour Using an Automatic Identification System
}

\author{
Leon Rothkrantz Krispijn Scholte
}

\begin{abstract}
The goal of our research is the design and implementation of an automated surveillance system based on an Automatic Identification System (AIS). The AIS system enables operators to monitor ship movements. Human observation 7 days in a week, 24 hours a day requires a lot of resources. There is a need to support human operators using an automated system modelled after human operator. The four steps Observation-Orientation-Decision-Action (OODA-loop) are realised using a rule based expert system and Bayesian network. The design, implementation and results of experiments are reported in the paper.

Key words: Expert systems, OODA-loop, AIS-Data, Bayesian networks, Surveillance systems.
\end{abstract}

\section{INTRODUCTION}

Since the increase of terroristic activities there is a need for a surveillance system along the coast of Europe to detect Intruders and suspicious ship movements. Vessels fitted with AIS transceivers and transponders can be tracked by AIS base stations located along coast lines or, when out of range of terrestrial networks, through a growing number of satellites that are fitted with special AIS receivers. Information provided by AIS equipment, such as unique identification, position, course, and speed, can be displayed on a screen or an ECDIS. The International Maritime Organization's International Convention for the Safety of Life at Sea requires AIS to be fitted aboard international voyaging ships with gross tonnage (GT) of 300 or more tons, and all passenger ships regardless of size. Currently ship movements are monitored by human operators in control rooms [3]. as displayed in Fig. 1,2.

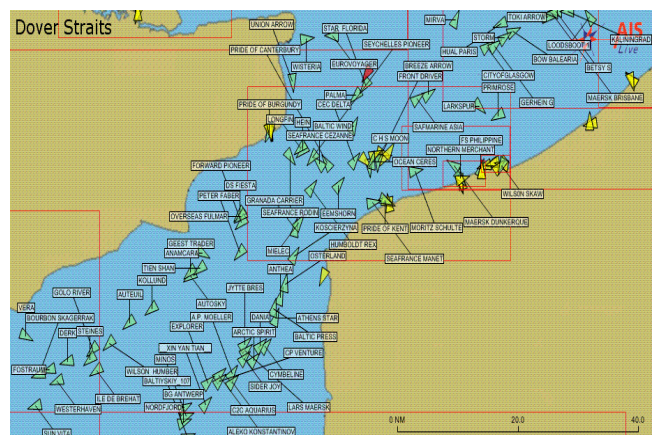

Figure 1: A graphical display of AIS data.

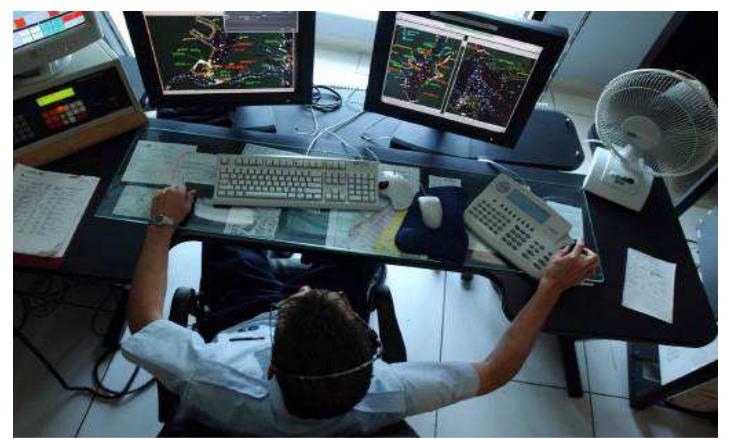

Figure 2: A marine traffic coordinator using AIS.

Monitoring ship movements 24 hours a day during 7 days in a week requires a lot of human resources. The surveillance job is of high importance but not very challenging. Intrusion of ships in forbidden areas, violation of the traffic rules and suspicious ship movements could be detected automatically using the ship tracks generated by AIS data. An alert will be generated to the control room, the event will be validated by human operators and if needed operators inform the Coast Guard or start a high alert procedure.

Processing kinematic information to detect and track ships is well developed. The scientific challenge of this paper is the real time semantic interpretation of the kinematic information and to detect the intent of ships. At this moment detection of behaviour and intent takes place in the mind of the operator in the control room. In this paper we try to extract the knowledge of the operator and emulate the reasoning of the operator in an automated system.

As a first step we developed a rule based system modelled after human operator. An operator is triggered by unusual events, generates a hypothesis about the possible ongoing situation, validates this hypothesis by new data and generates an action. This procedure is very similar to the well known Observation-Orientation-Decision-Action-loop 
(OODA) [1]. The knowledge/expertise of the human operator has to be extracted from the experts by interviews and comments of operators using simulated suspicious events. The knowledge of the operator is represented as if-then rules. CLIPS, a well known expert system shell [2] has been used to implement the knowledge rules and to design a reasoning procedure. Features extracted from the AIS system are fed into the expert system and the system generates possible actions. As a second step we developed a probabilistic model using Bayesian networks.

The developed systems should be able to perform:

- Auto Surveillance (deviation of speed direction route, boundary crossing).

- Protection of critical infrastructure such as strategic, military harbours and installation against piracy and terroristic attacks.

- Anomaly detection (unwanted behaviour, violation of traffic rules).

- Generating alerts and alarms after probabilistic or deterministic reasoning and processing of the observed AIS data.

The outline of the paper is as follows. In the next section we give an overview of related projects and research. Then we will present the model/architecture of the system. Next we will describe the knowledge database and implementation of a rule based expert system and Bayesian network. Finally we present the test results and conclusion.

\section{RELATED WORK}

AMASS (Autonomous Marine Surveillance System) [8] draws on the latest technology to provide a reliable, round-the-clock maritime monitoring solution. Unfortunately additional hardware is needed, our system is based on existing AIS technology. A line of buoys located offshore ensures comprehensive coverage of territorial waters. Each buoy is equipped with the latest visual and acoustic sensors. When a suspicious vessel is detected, images can be transmitted directly to a control centre on shore. This provides authorities with unprecedented observation capabilities an enables them to take swift appropriate action.

- INDRA [8] designs, builds and integrates state of-the-art surveillance systems for coastal and terrestrial supervision. These systems can be integrated with existing systems and networks to improve detection and coordination performances.

- HarborGuard Security and Surveillance System [8] is developed by Klein and based on small target detection radar. The system is designed to detect, monitor, track and identify very small targets such as small boats (jet skis, rubber boats etc.), surface swimmers, and floating mines. The system automatically monitors all target activity in the coverage area and compares the target's location and movements against programmable sets of alarm rules. An alarm automatically cues a camera on the target for identification and can trigger eternal deterrent components such as searchlights and loud hailers.

- Two NATO Centres of Excellence (Combined Joint Operations, Confined Shallow Waters) have taken the challenge of exploring maritime security issues and searching for global solutions. They jointly organised the Maritime Security Conference 2011 and a second joint Conference 2012 in Halifax [8].

Our paper is based on a research project running at the Technical University of Delft and The Netherlands Defence Academy focussed on the development of surveillance systems on public places [4], [6], [7]. 


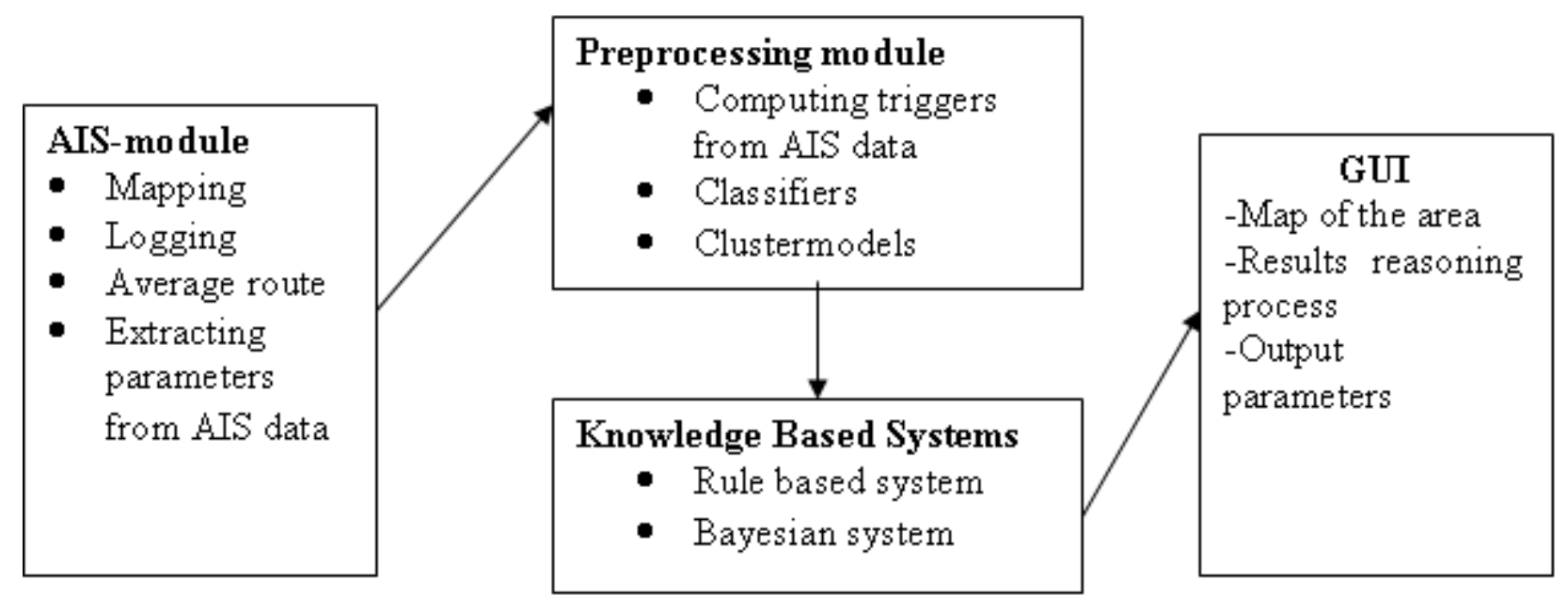

Figure 3: Architecture of the autonomous Surveillance system

In Figure 3 we display the architecture of our AIS-based surveillance system. It is composed of several modules. We will discuss the modules in more detail.

\section{- AIS-module}

Our research is focussed on the military/civilian harbour of Den Helder and its surrounding area (see Fig 4). We installed a special VHF antenna, AIS receiver and laptop with logging software in a tower at the entrance of the harbour. Ship movements are logged 24 hours a day from April $12^{\text {th }}$ until $28^{\text {th }} 2013$. Every day a file of about $150 \mathrm{Mb}$ data was logged containing 1.1 million AIS-messages. From those loggings we computed the average track for different kinds of ships (military ships, fisher boats, oil tankers etc.). Usually ships coming from the open sea enter the harbour area and go to the military area, civilian area or continue their route via the channel (see Fig 5). There are no predefined highways on open sea, but it proves from our loggings that ships take regular routes $n$ some areas (see Fig. 5). This enables our system to check if a ship takes an unusual or even forbidden route. To check if a ship violates other traffic rules we have to compute some parameters along a track.

If a new ship enters the area, the following data are logged: (1) identity of the ship, (2) position and (3) time. AIS data are updated with a sample rate of 2-10 seconds. From the discrete tracks we computed the following parameters over a selected time interval: (4) speed, (5) acceleration, (6) curvature of the track and (7) heading. The 7 parameters are attached as a vector to the ship along its track.

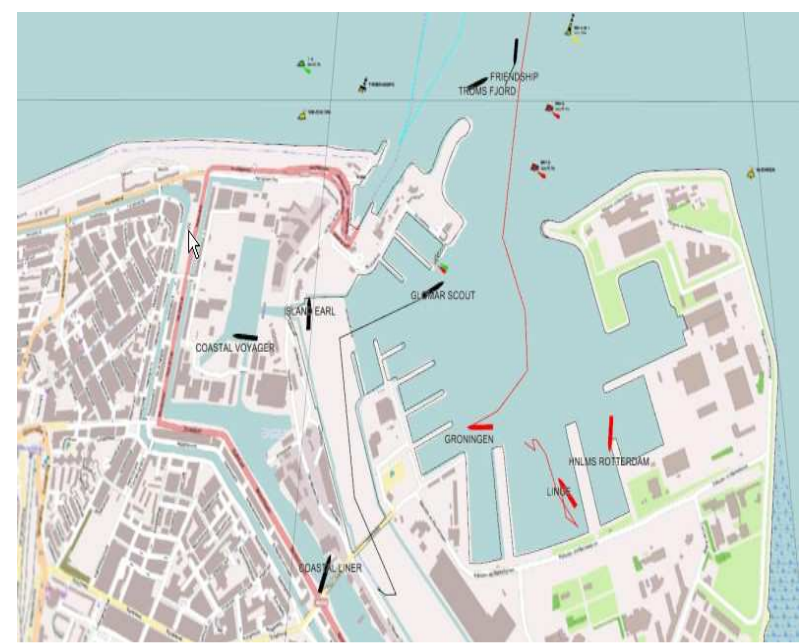

Figure 4: Map of the harbour of Den Helder

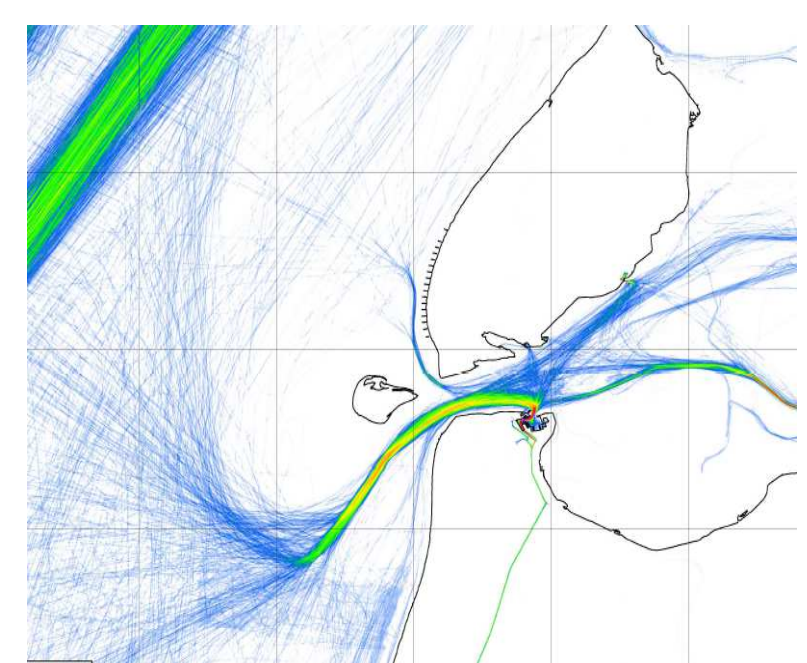

Figure 5: Map with ship routes 


\section{- Pre-processing module}

From the logged track of a ship and its corresponding parameters we compute the following events. In the reasoning module we will use these events as triggers to reason about.

Trigger 1 Time of the day

It is unusual, unwanted or even suspicious behaviour that some categories ships sail in some areas at a given time.

Trigger 2 Area or sector

Some categories of ships are not allowed without permission to sail in some area. Forbidden areas or areas with limited access are marked on the map.

Trigger 3 Personal space

Every ship is surrounded by an area shaped as an ellipsis. It is not allowed to enter this area without permission. There is a danger for collision or boarding.

Trigger 4 Speed limit

In some areas there is a speed limit. It is not allowed to violate this speed limit. In other areas it is not allowed to stop or to sail too slowly.

Trigger 5 Curved track

Usually ships sail in a straight line from a waypoint to the next. A zigzag at random course could be mechanical problems or drunken/ill sailor.

Trigger 6 Change of direction on unexpected place

The routes of ships are modelled as a graph. Usually ships change directions on the cross points. Changing route or turning around is not allowed along a route.

Trigger 7 Unwanted heading

A ship sailing in the direction of another ship or critical parts of the infrastructure is suspicious. Virtual lines are computed along the heading to detect possible hits or targets. Trigger 8 AlS switched of

As soon as a ship starts sailing, leaving the harbour or embarking places, it has to switch on his AIS system.

\section{- Knowledge Based System}

The goal of our research is to design an automated observation system based on AIS data to detect unwanted behavior of ships. Our system is modeled after the observation and reasoning of human operators in a control room.. As observation model we will use an adapted version of the OODA loop (Observation, Orientation, Decision, Action).

\section{Observation triggers}

The human observation system is sensitive to salient triggers from the environment. Observing the AIS data human operators get alerted by special behavior of ships such as location and changes in speed, course. Our system will extract parameter values from the AIS data and special values of these parameters corresponding with unusual behavior.

\section{Hypothesis}

If operators observe special patterns in AIS data a hypothesis pops up their mind. The hypothesis that will be generated depends of past experience and training of the operators [5]. The interpretation of the data is very context sensitive, dependent of place, time and situation. In our system if-then rules are defined between triggers and hypothesis.

\section{Validation}

A hypothesis has to be evaluated. An operator will actively search for new data supporting the hypothesis. If too many new data contradicts the hypothesis, the operator will give up the hypothesis and defines a new one. For every hypothesis we will define related supporting events, again defined as if-then rules.

\section{Action}

A positively evaluated hypothesis will induce some actions, varying from sending an alert to the Coast Guard, sending an SOS alert, activate the ship guards, or wait and see. 

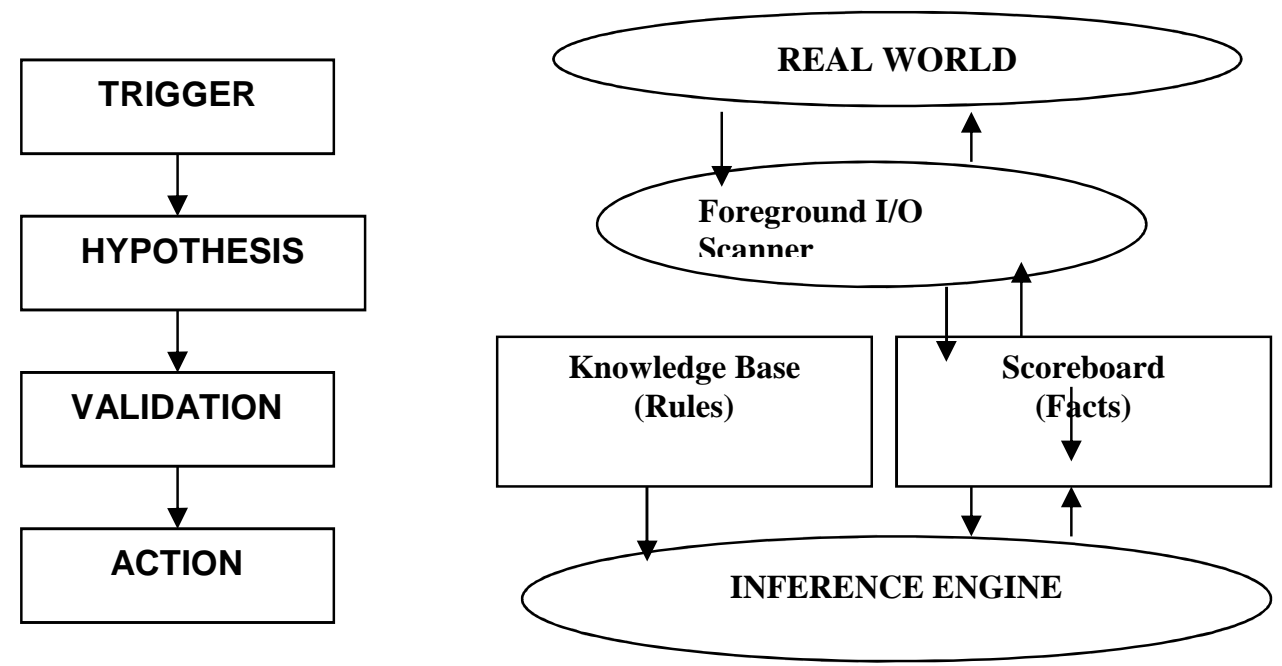

Figure 6: Reasoning procedure.

Figure 7: Architecture of a Production Rule System.

\section{IMPLEMENTATION OF THE SURVEILLANCE SYSTEM MODELS}

The goal of our research is to design a surveillance system modeled after human operator model. A human operator is able to observe and reason about AIS data on his computer screen. An operator has some expert knowledge acquired from training and experience. To design an automated reasoning system we have to extract the knowledge from the operators and design an expert system which is able to reason. We designed 12 scenarios about violation of rules, unwanted behaviour, terrorism and attacks of ships and critical infrastructure. We discussed these scenarios with military experts and defined for every scenario the triggers, hypothesis, validation and actions and probability of events.

The extracted elicited knowledge from experts is summarised in Table 1. In Figure 6 we display the general architecture of a rule based system. The kernel of the system is the Knowledge base, which is composed of if-then rules representing the knowledge of the expert. Observed facts are stored on a stack in the scoreboard module. The Inference engine is able to reason automatically as follows. If a fact $A$ is observed all the rules $A-B$ with left hand $A$ are selected and fact $B$ is concluded and added to the facts list. It will happen that more than one rule with left hand fact $A$ can be selected. The rules are processed in order of priority of the rules and a reasoning mechanism implemented in the rule based system. To implement our rule based system we used the well known CLIPS expert reasoning shell. The used knowledge is represented in Table 1. The 4 objects Trigger, Hypothesis, Validation and Action are liked together by three kinds of Rules $\mathrm{THi}$, $\mathrm{HVi}$ and VAi as follows:

\footnotetext{
IF <trigger> THEN Suggest <hypothesis > $<$ hypothesis> confirmed by <validation tests> If $<$ validation tests $>$ THEN DO <action $>$
}

The knowledge elicitation task is realised by interviewing the experts in the human control room. These experts are requested to report about their past experience using the OODA loop model. During monitoring the computer displays with AIS data they report about salient triggers, which hypothesis is generated, how they are evaluated and which action is generated. 
Table 1. List of rules, triggers, hypothesis, validation and action.

\begin{tabular}{|c|c|c|c|c|c|c|}
\hline Trigger (s) & $\begin{array}{l}\text { Rule } \\
\text { numb } \\
\text { er }\end{array}$ & Hypothesis & $\begin{array}{l}\text { Rule } \\
\text { number }\end{array}$ & Validation & $\begin{array}{l}\text { Rule } \\
\text { number }\end{array}$ & Action \\
\hline \multirow[t]{2}{*}{$\begin{array}{l}\text { Ship at high } \\
\text { speed }\end{array}$} & TH1 & Ship is fleeing & HV1 & $\begin{array}{l}\text { Heading is open } \\
\text { water }\end{array}$ & VA1 & $\begin{array}{l}\text { Stop-alert/alert } \\
\text { coastguard }\end{array}$ \\
\hline & $\mathrm{TH} 2$ & Ship is chased & HV2 & $\begin{array}{l}\text { Ship is tracked by } \\
\text { other ships }\end{array}$ & VA2 & Send an alert \\
\hline \multirow[t]{2}{*}{ Ship stops } & $\mathrm{TH} 4$ & $\begin{array}{l}\text { Ship has } \\
\text { mechanical } \\
\text { problems }\end{array}$ & HV4 & $\begin{array}{l}\text { Ship sends SOS } \\
\text { alerts, } \\
\text { explosion/fire/smoke } \\
\text { (camera sensor) }\end{array}$ & VA3 & Send an alarm \\
\hline & TH5 & Route is blocked & HV5 & $\begin{array}{l}\text { Blocking object on } \\
\text { the targeted } \\
\text { route/course }\end{array}$ & VA5 & Send an alert \\
\hline \multirow[t]{2}{*}{$\begin{array}{l}\text { Ship stops } \\
\text { Rubber ship is } \\
\text { launched from } \\
\text { mother ship }\end{array}$} & TH6 & Terroristic attack & HV6 & $\begin{array}{l}\text { Rubber boat is } \\
\text { heading with high } \\
\text { speed at critical } \\
\text { infrastructure }\end{array}$ & VA6 & Send an alarm \\
\hline & $\mathrm{TH7}$ & $\begin{array}{l}\text { Ship passengers } \\
\text { want to leave the } \\
\text { ship }\end{array}$ & & $\begin{array}{l}\text { Rubber boat is } \\
\text { heading to civilian } \\
\text { quay }\end{array}$ & & Tracking rubber boat \\
\hline \multirow[t]{3}{*}{ Ship is turning } & TH6 & $\begin{array}{l}\text { Ship is choosing } \\
\text { new course }\end{array}$ & HV7 & $\begin{array}{l}\text { Ship is at cross point } \\
\text { of different courses }\end{array}$ & VA7 & Track ship \\
\hline & & & HV8 & $\begin{array}{l}\text { Ship turns not at a } \\
\text { usual crossing point }\end{array}$ & VA8 & Send an alert \\
\hline & TH7 & $\begin{array}{l}\text { Ship is turning } \\
\text { back }\end{array}$ & HV9 & $\begin{array}{l}\text { Ship returns to old } \\
\text { course/track }\end{array}$ & VA9 & Track ship \\
\hline \multirow[t]{2}{*}{$\begin{array}{l}\text { Ship takes } \\
\text { unusual } \\
\text { route/course }\end{array}$} & TH8 & Ship lost his way & HV10 & $\begin{array}{l}\text { Ship keeps on } \\
\text { unusual route }\end{array}$ & VA10 & Send an alert \\
\hline & TH9 & $\begin{array}{l}\text { Trajectory/course } \\
\text { is suspicious }\end{array}$ & HV11 & $\begin{array}{l}\text { Ship is intruding } \\
\text { safety areas }\end{array}$ & VA11 & Send an alarm \\
\hline \multirow[t]{2}{*}{$\begin{array}{l}\text { Ship detected } \\
\text { at exceptional } \\
\text { time }\end{array}$} & TH10 & Late arrival & HV12 & $\begin{array}{l}\text { Ship sailing expected } \\
\text { route }\end{array}$ & VA12 & Track ship \\
\hline & TH11 & $\begin{array}{l}\text { Course is } \\
\text { suspicious }\end{array}$ & HV13 & $\begin{array}{l}\text { Ship is intruding } \\
\text { safety areas }\end{array}$ & VA13 & Send an alarm \\
\hline $\begin{array}{l}\text { AIS system of a } \\
\text { ship stops } \\
\text { sending data }\end{array}$ & TH12 & $\begin{array}{l}\text { Suspicious } \\
\text { behavior } \\
\text { Random error }\end{array}$ & HV14 & Track ship by radar & VA14 & Send an alert \\
\hline
\end{tabular}




\section{TESTS}

We first tested our preprocessing module. One of the problems was that about $5 \%$ of the AIS data was missing because of unstable public domain AIS device and AIS was switched of by the shipper. We installed a new AIS antenna on one of the towers in the harbor and the amount of missing data was reduced to less than $1 \%$.

The computation of the variables from the kinematic information AIS data was good in stable situations. But in case a ship accelerates very fast or makes sharp turne sthe data was unstable. We increased the observation window and with half overlapping observation windows of half a minute we were able to smooth the computed data.

To test the reasoning part of our system, many examples of forward and backward chaining were generated and validated succesfully. In Figure 7 we present an example.

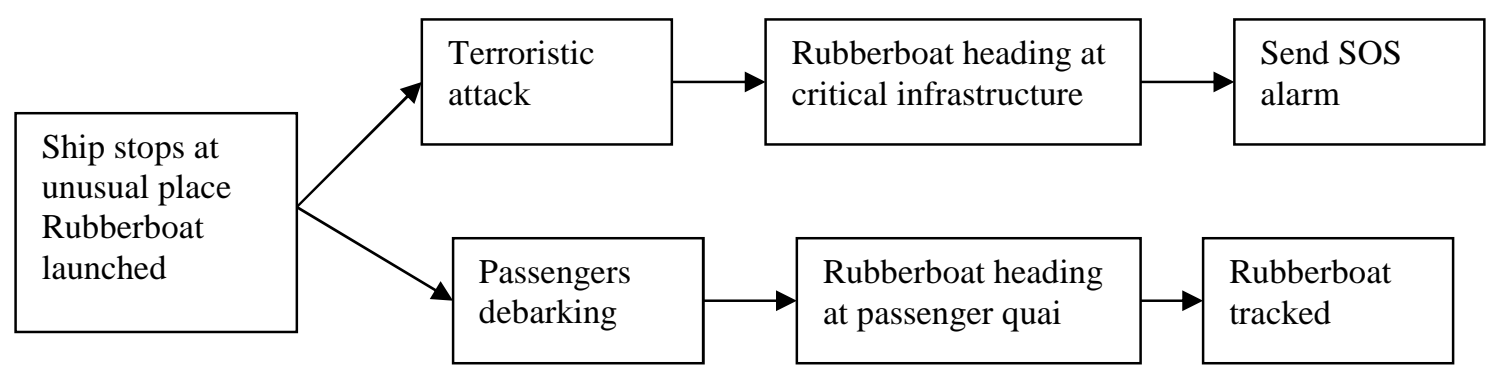

Figure 8: Example of forward reasoning.

One of the disadvantages of using a rule-based system is that IF-THEN rules are always deterministic. Either the IF-condition of the rule is fulfilled or it is not. A certain event or variable value may be an indication for more than one situation. For example, a ship at high speed approaching the harbour wants to embark as soon as possible or has hostile intents. We tried to solve this problem by introducing probabilities to determine the likelihood of the start and end of each using Bayesian networks. For every possible scenario we designed a model of a Bayesian network as in Fig 9. We research events with a very low frequency. So it is impossible to gather data by logging data for some time. Military experts have to set the values in the Conditional Probability Tables.

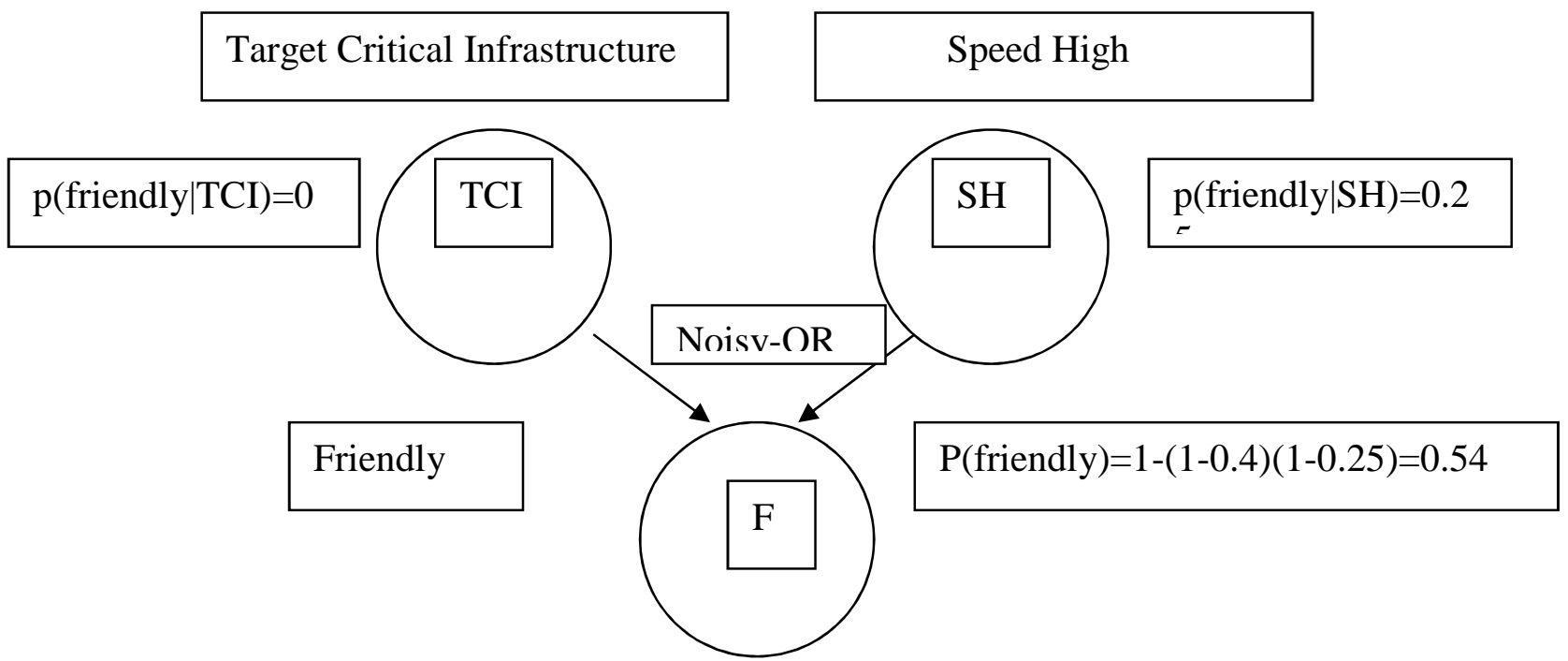

Figure 9 Example of Bayesian inference 


\section{CONCLUSIONS AND FUTURE WORK}

We were able to design an automated observation system for unwanted ship behavior. Using a rule based expert system or a probabilistic Bayesian system we were able to compute a semantic interpretation of the kinematic tracking AIS-data of ships We were able to reproduce the human reasoning process in all defined scenarios. The relative simple observation tasks performed by human operators enable the design of such an automated system. The system will play a role in a surveillance system of ship movements along the Atlantic Coast.

Unfortunately at this moment the system is not able to reason beyond predefined scenarios. But it proves that also human operators were not able to reason about new scenarios. A scenario based on a terroristic attack was not recognized because it never happens in the past and was considered as an impossible event. This is in correspondence with the ideas of Klein [5]. He claims human operators generate a hypothesis using their experience if they are confronted with triggers. Human operators are unable or not willing to consider alternatives simultaneously. They stick to the first hypothesis and give it up only if many contradictory data becomes available which support an alternative. Our surveillance system is able to reason about many hypotheses in parallel.

In the current version of our surveillance system we use only the kinematic data of AIS. But AIS can provide more information for example about the ship type and cargo. It is a great difference if an oil tanker, full of gas or oil is approaching the harbor or a fisher boat. Additional AIS-information will be included in the next version of our surveillance system.

\section{REFERENCES}

[1] Boyd, J., R. Destruction and Creation, US Army Command and General Staff College, September 3, 1976.

[2] Boullart, I., A. Krijgsman, R. Vingerhoeds. Application of Artificial Intelligence in Process Control, Elsevier Science Limited, 1992.

[3] Vessel tracking and Automatic Transmitter Identification System (marine), http://en.wikipedia.org/wiki/Automatic_Identification_System.

[4] Hameete, P., S. Lejjsen, T.van der Laan, I. Lefter, L. Rothkrantz. Intelligent MultiCamera Video Surveillance. International Journal on Information Technologies and Security (IJITS). 4:51-62, 2012.

[5] Klein, G. Sources of Power: How People Make Decisions Cambridge, MA: MIT Press, 1999.

[6] Lefter, I., L. Rothkrantz, M. Somhorst. Automated safety control by video cameras. International Conference on Computer Systems and Technologies (CompSysTech'12). 298-305, 2012.

[7] Wiggers P., Mertens, B., Rothkrantz, L. 2011. Dynamic Bayesian Networks for Situational Awareness in the Presence of Noisy Data. International Conference on Computer Systems and Technologies, (Compsystech'11). 578:411-416.

[8] www.maitimesecurityconference.org.

\section{ABOUT THE AUTHOR}

Prof. Leon Rothkrantz, PhD, Department Intelligent Interaction, Delft University of Technology, Department Sensor, Weapons, Command and Control, Netherlands Defence University Phone: +31152787504, E-mail: L.J.M.Rothkrantz@tudelft.nl

LTZE2OC Crispijn Scholte. Dutch Navy 
